\title{
Cluster Typology of Business Models of Start-Ups. (Example of Slovakia)
}

\author{
Štefan Slávik ${ }^{1, * \mathbb{D}}$, Richard Bednár ${ }^{1} \mathbb{B}^{\mathbb{B}}$, Ivana Mišúnová Hudáková $^{1}$ \\ and Katarína Moravčíková 2,3 (iD) \\ 1 Department of Management, University of Economics in Bratislava, 85102 Bratislava, Slovakia; \\ richard.bednar@euba.sk (R.B.); ivana.misunova@euba.sk (I.M.H.) \\ 2 Department of Statistics, University of Economics in Bratislava, 85102 Bratislava, Slovakia; \\ katarina.moravcikova@euba.sk \\ 3 Institute for Forecasting CSPS, Slovak Academy of Sciences, 81105 Bratislava, Slovakia \\ * Correspondence: stefan.slavik@euba.sk
}

Received: 17 July 2020; Accepted: 7 August 2020; Published: 11 August 2020

\begin{abstract}
Start-up is an emerging micro-enterprise that has different characteristics to a larger and mature enterprise. Its viability depends mainly on a functioning business model. The purpose of the research study is to identify the basic types of business model regardless of the specific industry, and thus to penetrate deeper into the more general cognition of start-up business making. The research sample contains 106 start-ups, the business models of which are described using fourteen criteria, which are derived from the visualization of canvas. The research sample is divided by cluster analysis (Ward's hierarchical agglomeration method) into nine clusters, hence types of business models. For a better understanding, the clusters were aggregated into four groups with similar business models. Grouping A is characterized by the model with a small range of processes, mostly with higher product differentiation, scarce resources and satisfying the common basic and higher needs. Grouping B is characterized by the model with a large range of processes and higher product differentiation and satisfying the common basic and higher needs or newer practical needs. Start-ups in grouping C have the model with considerable differentiation aimed at satisfying the common needs. Grouping D has the model based on cultivating relationships with customers, cheap satisfying of needs and use of ordinary resources. The models differ the most in the span of operational processes, segmentation and distribution, and differ the least in the relationships between customers, the cost-price ratio and protection against imitation. The practical use of the identified clusters lies in the fact that they are a reflection of the real behaviour of start-ups, they determine the real parameters of business models, and therefore they provide the founders of start-ups with verified patterns, the outlines of which are probably not definitive.
\end{abstract}

Keywords: business model; start-up; cluster analyses; typology of business models

\section{Introduction}

Business models are considered an important topic for business practice and scientific research, because they clarify and justify the elementary viability of the company (Baden-Fuller and Mangematin 2013), the purpose of its existence, predetermine its competitive advantage and are the core of business strategy. The research of business models is more focused on larger and mature companies, but there is also a need to make research of very small and emerging companies, i.e., start-ups (Ghezzi and Cavallo 2020). A functioning and robust business model (Haaker et al. 2017) is a basic existential assumption of a start-up. While mature companies already have some models, the founder of a start-up must create a business model from scratch (Blank 2013). 
Business model research, according to Ritter and Lettl (2017), has five trends, one of which is deals with model archetypes. Archetypes have a higher degree of generalization and differ in the value offered. Archetypes (taxonomy, typology) of business models and their research can bring a holistic and, at the same time, structured view of the hitherto little-ordered business entity, which in the sphere of start-ups has even more obscure contours than in the world of mature companies. Criteria-defined types of business model will bring new knowledge about start-ups and can also be a useful guide for starting entrepreneurs.

The research goal, the problem, the question is, what business models do start-ups have? What is their structure? Are they the same or different, exactly the same or completely different, or are they similar? What is important or typical for them? The miniature dimension of start-ups suggests that the differences, if any, cannot be large. Business models of mature enterprises (incumbents) are known much better (Gassmann et al. 2014). Business models of start-ups are known in the basic structure (Slávik 2019), but without further classification and categorization.

The aim of the research is, hence, to categorize the business models of start-ups, and thus to clarify the behavior of companies of this kind at the beginning of their business cycle. Criteria-defined types of business model will bring new knowledge about start-ups and can also be a useful guide for start-ups. Data on business models of start-ups are collected in field research and processed using the method of cluster analysis. The research sample is not internally structured or profiled to highlight the generic nature of business model types/clusters. The article describes the current state of knowledge about business models, especially start-ups; further, there is described research sample and an explained analytical method. The results are categorized into clusters, but due to their number they are combined into a smaller number of groups for a more concentrated interpretation. The discussion and conclusions show the knowledge that has been achieved in the researched topic.

\section{Typology of Start-up Business Models}

A start-up is a young company that searches for an unknown business model in order to disrupt existing markets or create new ones (Surbhi 2016). A startup is a temporary business model designed for a repeatable and scalable business model (Graham 2018) whose essence is rapid growth, which is also adapting its strategy (Muramalla and Al-Hazza 2019). Understanding it is important not only because the best of them are worth millions of dollars (Zepeda and Brandel 2019), but also because they create new jobs and bring solutions to existing problems from ecology, economics and communication to relaxation and entertainment. The growing role that start-ups play in the overall economy is putting pressure on a lot of academic research to build theories that link innovation and entrepreneurship (Schane and Ulrich 2004). The number of start-ups is constantly growing. There are 215,557 startups registered in the USA, 76,237 in Europe and 78,501 in Asia (Angelist 2019).

The main problem of start-ups is their failures. The most important factor is the early launch of a start-up. Most start-ups have mismanaged expectations, illogical budgets, and insufficient plans (Schrage 2018). A study by Iwu (2017) has shown that 1 in 12 start-ups will end in 2-3 years because they face many challenges. The most important challenge is the ability to sell the start-up idea. After the product is launched, the company expects customers that do not exist or are unwilling to pay for the product (Downes and Nunes 2018). However, the main problem of all start-ups is the setting the business model. CB Insight (2018) analyzed 101 failed companies and most failed founders agree that it is most important to have the right business model. Startup Genome (Global Start-up Ecosystem Report 2019) analyzed 34,000 business models and found that one of the most important success factors is to find a balance in the start-up business model: on the one hand there are users, customers, product use and revenues, and on the other side there are customer relationships, product, team, finance and law.

It follows that every successful business formation should have an effective conceptual and economical idea of how the enterprise works and how it makes money. In defining the business model, it is most difficult to identify those processes and components that would comprehensively outline how the business works. Magretta (2010) explains that a business model is an answer to four 
questions: Who is a customer? How do we make money? What is the basis of our business? How do we deliver the value to the customer with appropriate costs? The result of the 26 Circular Economy Business Model Patterns uses four business model dimensions (Lüdeke-Freund and Bocken 2018): value proposition (products, services), value delivery (target customers, value delivery processes), value creation (partners and stakeholders, value creation processes) and value capture (revenues, costs). Study of Zhang (2018) identified six components of a business model: the consumer, the niche, the delivery, the revenue, the funding model, and the profit-sharing model. According Rappa (2010), a business model is a method to generate revenue and to bring value. Johnson et al. (2008) see a business model consisting of four elements that are interconnected and create value in the enterprise: benefits of customer value, profit formula, key resources and key processes. Afuah (2003) divides the business model into a few key components: industry factors, resources, position, costs and activities. Osterwalder and Pigneur (2009) and 470 collaborators divide a business model into nine blocks: customer segments, the added value, channels, customer relationships, revenue streams, key resources, key activities, key partners and cost structure.

One of the steps toward developing more theoretical insight and practical guidelines is the identification of business model types and the development of a typology of business models. According to Wirtz (2019), there are four types of B2C business models: focusing on content, commerce, context and connection. Another theory (Rask and Franziska 2019) proposed a two x two typology of business model choices and performance where the four types of business models distinguish themselves by how the companies innovate or imitate the value proposition of the current industry as well as how they innovate or imitate the business model archetype: The Infrastructure start-up, The Manufacturer start-up, The Incumbent Manufacturer and The Infrastructure Incumbent.

Research at two Finland universities (Hokkanen et al. 2016) identified that the core of business models is about value creation and its capture. Most of the researchers created typology in specific industries. The research (Hansen 2018) in the e-mobility industry brought four patterns of business models categorized by means of two dimensions, namely value proposition and value creation: The '(predominantly) simple use' pattern, The 'complementary business' pattern, The 'feedback to core business' pattern and The 'additional business model' pattern. The research at University of Freiburg (Rückeshäuser 2017) identified five types of business models based on distributed ledger technology: Data infrastructure provider, Development facilitator, Integration enabler and Supporting or supplementary service provider. Study at Université Laval in Québec, Canada (Rougès and Montreuil 2014) analyzed 18 start-ups in the crowdsourced delivery industry and proposed a typology of five archetypal business models: Courier, Intendant, Intra-urban, National and Social delivery. Other research (Henry et al. 2020) created five circular start-up archetypes: design-based, waste-based, platform-based, service-based and nature-based start-ups. Research at the Osnabrück University (Beinke et al. 2018) using cluster analysis created seven types of business models: trading platforms, payment applications, software solution provider, credit cards, wallet-provider, applications for business and private customers and payment applications for business. The University of Goettingen (Remane et al. 2016) identified, in the US mobility sector, 14 digital business model types: app developer, autonomous products/robots manufacturer, data analytics provider, integrator of third-party services, IT-enabled self-service provider, IT-guided service provider, manufacturer of connected physical products, manufacturer of connectivity devices for physical products, mobilized service provider, P2P goods sharing platform, P2P information-sharing community, P2P service provision platform, seller of sensor information, and sensor-enabled service innovator. Novak and Hoffman (Sahut et al. 2013), have presented a "Customer Model Integration" in which the definition of an e-BM is related to both "the value patterns for customers" (value model) and "revenue models" (revenue model). It is then possible to identify twelve model values: brokerage, content, search, incentive, freeware, communication, control, outsourcing, entertainment, transaction, affiliate and community. A study of journalistic start-ups (Zhang 2018) identified five business models: platform-oriented news aggregator, platform-oriented service provider, content-oriented news site, 
content-oriented trade journal, and content-oriented e-media. Typology of electronic business models for financial services (Sahut 2011): vertical portal, aggregators (brokers and quoters), speciality manufacturer and company sites. Other research (Donner et al. 2020) identified four types of business models in the circular economy: biogas plant, upcycling entrepreneurship, environmental bio-refinery, agricultural cooperative, agricultural park and support structure. The research at the University Sydney (Bryant et al. 2018) created BM typology in the energy sector: the green energy utility, the cooperative energy utility, the prosumer energy utility, and the prosumer facilitator. Another typology (Schweizer 2005) consists of four different types of business model: integrated, layer player, market maker and orchestrator. Muñoz and Cohen (2017) analysed business models of 36 firms in the sharing economy using comparative method fs/QCA. They leveraged seven dimensions of sharing economy business models and created five ideal types of business models across the sharing economy. This research is, again, specific because it emphasizes the shared economy and, in addition, some companies in the research sample can no longer be considered as start-ups.

Corbett and Katz (2016) took a completely different approach to business making with start-ups. The publication they edited is dominated by business plans, which, however, cannot be considered the main tool for the development of start-ups. Business plans rarely survive the first contact with customers. Planning into the unknown is a fiction and start-ups move forward by trial and error. The business model is considered a more necessary and accepted tool (Blank 2013).

All these typologies are not complex and universal. They are mostly aimed to specific industry and use various frameworks of criteria to visualize a business model. There is an absence of a general and comprehensive typology of business models based on a unified framework, which could bring generally recognized knowledge and provide a complete view for strategic decision-making purposes (Franco et al. 2016). Almost all research uses case studies as a research tool; there is little research based on larger samples and analyzed by statistical methods. An integrated typology can provide fundamental ready-made solutions that founders of start-ups can use as a starting point and inspiration, transfer to their own company and adapt to their customers' and their own business needs. This kind of typology can also be used for assessing the performance of individual solutions (Zajac 2015). An un-negligible consequence is a possibility to compare business models of start-ups across various industries.

\section{Objective, Research Sample and Research Methods}

The aim of the research is to expand and deepen knowledge about business models of start-ups, which are one of the fundamental conditions for their existence and survival. The state of birth, extremely limited resources, an uncertain future, and elementary entrepreneurship are circumstances that impose special characteristics on business models. The aim of the research is, therefore, to categorize the business models of start-ups into separate groups/clusters, which differ in their distinctive and typical features. In the background of considerations of the goal is the assumption that there is a finite number of relevant business models that are typical for start-ups. Clusters will make it possible to better know the characteristics of business models of start-ups, their occurrence in the population of start-ups and to identify their exemplary representatives.

The research sample initially contained 187 companies; it was reduced to 106 start-ups, because duplicate companies, companies with incomplete data and companies whose nature did not correspond to the characteristics of the start-up were excluded. The studied start-ups were established in 2014 and later, with the exception of five start-ups, established in the period 2012-2014. The average number of employees in the examined start-ups was 9.3. If three start-ups with more than 50 employees are excluded, the average number of employees falls to 7.12 .

A very small emerging company under the age of five years (only exceptionally and justifiably more) was considered a start-up, if meets the following parameters:

- The assumption of rapid, scalable to exponential growth; 
- The use of the personal savings of the founder and his/her immediate surroundings, angel capital, venture capital and resources resulting from own business-making to finance and sustain his/her operation;

- The business is based on (at least one condition must be met):

- A new original technology, or;

- A significantly improved use of existing technology, or;

- Discovering and satisfying a completely new need, or;

- Inventing/creating and satisfying a completely new need, or;

- Meeting an existing need in a significantly better or cheaper way.

Each start-up was examined by one member of the research team, who personally recorded the evaluations and answers of the founder/owner to the closed and open questions in the questionnaire and immediately explained any ambiguities. The questionnaire was divided into the following basic parts: personnel identification, establishment of start-up and initial investment, description of the business idea, description of the business model/blocks of canvas, summarizing evaluation/positive and negative experiences, pivots. Other sources of knowledges were interviews with team members, additional interviews as needed, publicly available information about the researched start-ups from their websites, and other websites, e.g., finstat (https://www.finstat.sk/), startitup (https://www.startitup.sk/) and professional magazines, which also served as additional control and correction. Field research took place in the period from September to November 2019 in the Slovak Republic and start-ups are mainly based in the capital Bratislava and its surroundings. Field research took place in the period from September to November 2019 in the Slovak Republic and start-ups are mainly based in the capital Bratislava and its surroundings.

Industry incorporation of researched start-ups according to Nomenclature statistique des économiés économiques dans la Communauté européenne (SK NACE):

A-Agriculture (forestry and fishing) -2

C-Industrial production-22

G-Wholesale and retail trade-10

I-Accommodation and food services-3

J-Information and communication-41

$\mathrm{K}$-Financial and insurance activities-1

M-Professional, scientific and technical activities-18

$\mathrm{N}$-Administrative and support service activities-1

$\mathrm{P}$-Education-4

$\mathrm{R}$-Arts, entertainment and recreation-1

$\mathrm{S}$-Other activities-3

Methods. Canvas visualization was used to display the start-up business model (Osterwalder and Pigneur 2009), which divides the model into nine blocks: customer value proposition, customer segments, customer relationships, distribution channels, key activities, key resources, key partners, cost structure, revenue streams. This model is sufficiently concise, has greater but limited detailedness, and therefore was used in the field research. Each block is described using open qualitative questions and closed quantitative questions. Answers are quantified, if possible, in real units. If this is not possible, they are expressed as shares in \% or usually on a five-point scale. The minimum granted value (1) means, e.g., lowest quality, simple solution, local level, high costs, current standard, mass market. Maximum value awarded (5) means world quality, sophisticated solution, world class, low cost, complete original, customization, etc.

The business model as an object of research is described using fourteen criteria/variables that express the essential properties of canvas visualization blocks (Table 1). These variables are subjected to cluster analysis. Cluster analysis is one of the classification statistical methods that deal with the 
investigation of the similarity of multidimensional objects. These are objects that are described by a larger number of characters (variables). Cluster analysis is used to look for similarities in diversity, in this case, start-ups that are characterized by common, specific characteristics (variables). The result is a certain typology of objects according to variables that are relevant for the analysis.

Table 1. Descriptive criteria of the business model.

\begin{tabular}{|c|c|}
\hline Blocks of Business Model & Criteria/Variables \\
\hline Customer value proposition & $\begin{array}{l}\text { 1. Product differentiation: } 1-5 \text { (standard/no } \\
\text { differentiation-original/unique) }\end{array}$ \\
\hline Customer segments & 2. Market segmentation: 1-5 (mass character-customization) \\
\hline Customer relationships & 3. Type of relationship to customers: $1-5$ (self-service shop-co-creation) \\
\hline Distribution channel & 4. Type of distribution channel: $1-5$ (direct-indirect) \\
\hline Key resources & $\begin{array}{l}\text { 5.1 Rarity of resources: } 1-5 \text { (accessible-inaccessible) } \\
\text { 5.2 Imitability of resources: } 1-5 \text { (imitable-inimitable) }\end{array}$ \\
\hline Key activities & $\begin{array}{l}\text { 6.1 Extent of own operational processes (number): } 1-9 \\
6.2 \text { Position/focal point of own operational processes: } 1-5\end{array}$ \\
\hline Key partners & $\begin{array}{l}\text { 7.1 Partners: number } \\
\text { 7.2 Deliveries from partners: } 1-3 \text { (resources, implementation processes, sale) }\end{array}$ \\
\hline Cost structure & $\begin{array}{l}\text { 8.1 Ratio of cost to price: } 1-5 \text { (high-low) } \\
\text { 8.2 Ratio of fixed to variable cost: } 1-5 \text { (high fixed-high variable) }\end{array}$ \\
\hline Revenue streams & $\begin{array}{l}\text { 9.1 Payment for kind of usefulness: } 1-4 \text { (new } \leftrightarrow \text { identical/cheaper) } \\
\text { 9.2 Payment for kind of need: } 1-7 \text { (health, security, satisfaction of material } \\
\text { or mental need/necessity } \leftrightarrow \text { comfort } \leftrightarrow \text { entertainment, relaxation) }\end{array}$ \\
\hline
\end{tabular}

Source: own research concept.

Dividing a research sample into several different groups using cluster analysis compartmentalises, clarifies and organizes the research sample. Cluster analysis is a multidimensional statistical method that is used to identify groups (clusters) on the base of measured variables. The essence of the method lies in the decomposition of an aggregate (grouping of objects $X_{i}$, where $i=1,2, \ldots, n$ ) into several groups (clusters $C_{1}, C_{2}, \ldots, C_{q}$, where $2 \leq q \leq n$ ), while objects in groups are as similar as possible to each other and, conversely, objects belonging to different clusters are ganged as least similar. Cluster analysis (Stankovičová and Vojtková 2007) is focused on the objects (statistical units), while other methods are focused on variables (statistical attributes). Cluster analysis makes it possible to radically reduce the complexity of the task, because numerous variables are substituted by the affiliation with the identified cluster.

Clustering is performed by Ward's hierarchical agglomeration method, which is considered to be the most widely used clustering method. It tries to form stable and approximately similar large groups (clusters), tending to remove small clumps. Hierarchical agglomeration (merging) methods are based on the gradual merging of objects from the most similar to the least similar. The first level consists of individual objects as separate clusters, and in the last level, the individual objects are merged into a single cluster. Ward's method forms clusters by maximizing internal homogeneity, whereas the distances between clusters are not counted. The degree of homogeneity is calculated as the inside cluster sum of squares of the deviations from the cluster average (error sums of squares (ESS)). The condition for joining objects into clusters at individual levels is to achieve a minimum increment of ESS.

$$
\text { Ess }=\sum_{\mathrm{i}=1}^{\mathrm{n}_{\mathrm{h}}} \sum_{\mathrm{h}=1}^{\mathrm{q}}\left(\mathrm{x}_{\mathrm{hi}}-\overline{\mathrm{x}}_{\mathrm{Ch}}\right)^{2}
$$

where: 
$\mathrm{n}_{\mathrm{h}}$-number of objects in cluster $\mathrm{C}_{\mathrm{h}}$;

$X_{h i}$-the vector of values of the character of the i-th object in the cluster $C_{h}$;

$\bar{X}_{\mathrm{Ch}}$-vector of averages of character values in the cluster $C_{h}$.

A statistically significant number of clusters can be assessed heuristically on the basis of a subjective opinion of the solver, who chooses a logical and interpretable solution. Another possibility is represented by means of the characteristics determining the quality of the clustering at each level. These are the semi-partial coefficient of determination (SPRSQ) and the coefficient of determination (RSQ). These coefficients are shown in the scatter plot (Figure 1). A significant break occurred in the ninth cluster, and therefore the analysis is limited to nine statistically significant clusters. Other values of the coefficients do not differ significantly and decrease or increase slowly.

The condition for performing the cluster analysis is that there is no statistically significant dependence between the input variables. In the examined sample, there are several cases that did not meet this condition, so their p-values are below the level of significance, and therefore the relationship between them is statistically significant. A violation of conditions occurred only in a small number of cases, which due to the size of the database can be tolerated and left in the analysis (Table 2).

Table 2. Pearson correlation matrix of descriptive criteria of business model.

\begin{tabular}{|c|c|c|c|c|c|c|c|c|c|c|c|c|c|c|}
\hline & 1. & 2. & 3. & 4. & 5.1 & 5.2 & 6.1 & 6.2 & 7.1 & 7.2 & 8.1 & 8.2 & 9.1 & 9.2 \\
\hline 1. & 1.0 & & & & & & & & & & & & & \\
\hline 2. & $0.249^{* *}$ & 1.0 & & & & & & & & & & & & \\
\hline 3. & 0.011 & 0.194 * & 1.0 & & & & & & & & & & & \\
\hline 4. & -0.106 & -0.015 & 0.099 & 1.0 & & & & & & & & & & \\
\hline 5.1 & 0.122 & 0.132 & $-0.192 *$ & 0.083 & 1.0 & & & & & & & & & \\
\hline 5.2 & 0.133 & 0.086 & -0.115 & 0.049 & $0.221 *$ & 1.0 & & & & & & & & \\
\hline 6.1 & 0.052 & -0.111 & 0.089 & 0.017 & 0.003 & -0.025 & 1.0 & & & & & & & \\
\hline 6.2 & -0.01 & -0.041 & 0.081 & -0.050 & 0.01 & 0.04 & $0.845^{* *}$ & 1.0 & & & & & & \\
\hline 7.1 & 0.068 & $-0.263^{* *}$ & -0.079 & 0.073 & -0.111 & 0.009 & 0.185 & 0.054 & 1.0 & & & & & \\
\hline 7.2 & -0.099 & -0.030 & -0.139 & 0.125 & 0.196 * & 0.001 & 0.105 & 0.022 & $0.305^{* *}$ & 1.0 & & & & \\
\hline 8.1 & 0.173 & -0.024 & -0.130 & -0.040 & 0.046 & 0.007 & 0.051 & 0.151 & -0.044 & 0.073 & 1.0 & & & \\
\hline 8.2 & 0.125 & 0.131 & -0.039 & 0.067 & 0.060 & $0.187^{*}$ & 0.003 & 0.028 & -0.088 & 0.149 & 0.009 & 1.0 & & \\
\hline 9.1 & -0.126 & 0.001 & -0.084 & -0.003 & 0.135 & -0.098 & -0.088 & -0.142 & -0.019 & -0.063 & -0.050 & 0.03 & 1.0 & \\
\hline 9.2 & -0.047 & 0.037 & -0.061 & -0.175 & -0.076 & -0.156 & -0.021 & 0.011 & $-0.204^{*}$ & -0.068 & 0.075 & -0.023 & -0.044 & 1.0 \\
\hline
\end{tabular}

Source: own research data; ${ }^{* *}$ significance $\leq 0.01 ;{ }^{*}$ significance $\leq 0.05$.

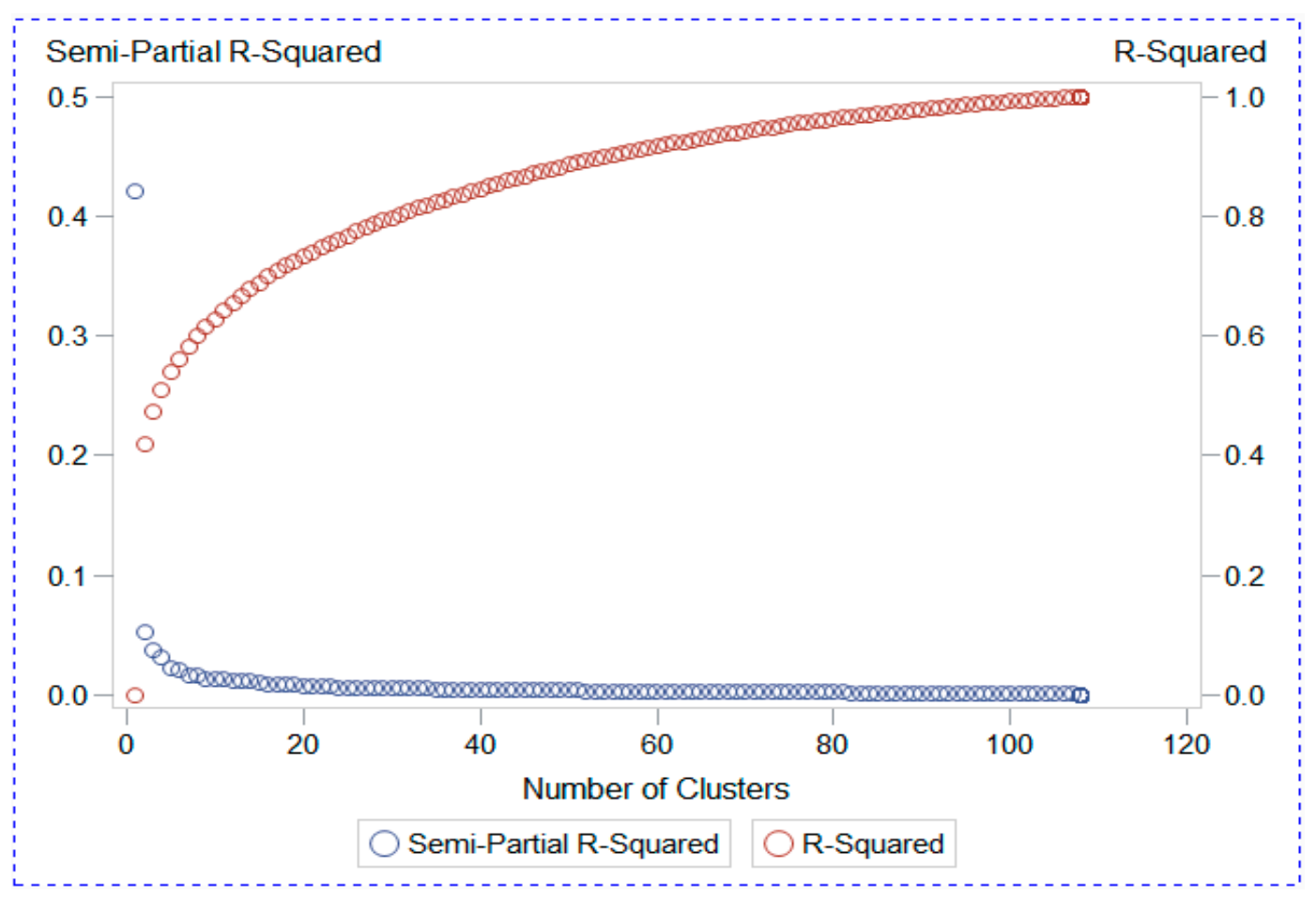

Figure 1. Scatter plot. Source: own research data. 


\section{Research Results}

The results of the cluster analysis were normalized on a scale from zero to one to allow a transparent and simple comparison of the identified clusters (Table 3). Particular clusters were characterized on the basis of variables whose values are extreme within the given possibilities, hence they are maximum or minimum in comparison with other clusters. Variables whose values are placed between extremes are not considered indicative because they do not differ much from the values of the variables of other clusters. In the characteristics of the clusters, terms were used, the content of which may not be completely obvious, and therefore their explanation is as follows:

* $\quad$ Minimalist $/$ maximalist model $=$ minimum $\leftrightarrow$ maximum range or length of internal operational processes, possibly more minimum/maximum criteria values

* Autonomous model/open model $=$ few partners $\leftrightarrow$ more partners,

* $\quad$ Payment for value/usefulness = satisfaction of a completely new need, new benefit $\leftrightarrow$ better, greater satisfaction of the ordinary need, more benefit $\leftrightarrow$ the same, but cheaper satisfaction of the ordinary need, cost savings $\leftrightarrow$ the same, but more accessible, prompt or faster satisfaction of the ordinary need,

* $\quad$ Payment for satisfaction of need $=$ health $\leftrightarrow$ safety $\leftrightarrow$ practical benefit, satisfaction of material or mental need, e.g., food saturation or finding the required information $\leftrightarrow$ experience $\leftrightarrow$ comfort $\leftrightarrow$ enjoyment $\leftrightarrow$ entertainment.

Table 3. Normalized results of cluster analysis.

\begin{tabular}{|c|c|c|c|c|c|c|c|c|c|c|}
\hline \multirow{2}{*}{ Criteria/Variables } & \multicolumn{10}{|c|}{ Clusters } \\
\hline & 1 & 2 & 3 & 4 & 5 & 6 & 7 & 8 & 9 & Difference \\
\hline 1. Product differentiation & 0.82 & 0.74 & 0.60 & 0.90 & 0.63 & 0.95 & 0.63 & 0.50 & 0.80 & 0.45 \\
\hline 2. Market segmentation & 0.75 & 0.45 & 0.42 & 0.40 & 0.43 & 0.90 & $\underline{0.33}$ & $\overline{0.40}$ & 0.52 & 0.57 \\
\hline 3. Relationship to customer & 0.57 & 0.58 & 0.51 & 0.54 & $\underline{0.43}$ & 0.48 & $\overline{0.59}$ & 0.50 & 0.53 & 0.16 \\
\hline 4. Distribution channel & 0.31 & 0.35 & 0.30 & 0.44 & $\overline{0.23}$ & $\underline{0.25}$ & 0.57 & 0.85 & 0.34 & 0.62 \\
\hline 5.1 Rarity of resources & 0.62 & 0.64 & 0.59 & 0.54 & $\overline{0.79}$ & $\overline{0.67}$ & $\underline{0.45}$ & 0.76 & 0.61 & 0.31 \\
\hline 5.2 Imitability of resources & 0.71 & 0.66 & 0.61 & 0.66 & 0.67 & 0.62 & $\overline{0.69}$ & 0.67 & 0.60 & 0.11 \\
\hline 6.1 Extent of operational processes & 0.12 & 0.94 & 0.15 & 0.12 & $\underline{0.16}$ & 0.36 & 0.56 & $\underline{0.11}$ & $\overline{0.90}$ & 0.83 \\
\hline 6.2 Focal point of operational processes & $\overline{0.57}$ & 0.93 & $\overline{0.51}$ & $\overline{0.44}$ & $\overline{0.54}$ & 0.60 & 0.70 & $\overline{0.40}$ & 0.86 & 0.53 \\
\hline 7.1 Number of partners & $\underline{0.16}$ & 0.28 & 0.32 & $\overline{0.63}$ & 0.31 & 0.32 & 0.55 & $\overline{0.25}$ & 0.66 & 0.5 \\
\hline 7.2 Deliveries from partners & $\overline{0.38}$ & 0.48 & 0.47 & 0.57 & 0.52 & 0.79 & 0.58 & 0.58 & 0.62 & 0.41 \\
\hline 8.1 Cost/price & $\overline{0.53}$ & 0.58 & 0.55 & 0.56 & 0.66 & 0.50 & 0.53 & 0.55 & 0.60 & 0.16 \\
\hline 8.2 Fixed/variable cost & 0.65 & 0.59 & $\underline{0.46}$ & 0.54 & 0.83 & $\overline{0.70}$ & 0.73 & 0.65 & 0.56 & 0.37 \\
\hline 9.1 Payment for kind of value/usefulness & 0.47 & 0.53 & $\overline{0.54}$ & 0.50 & 0.93 & 0.50 & 0.58 & 0.44 & 0.40 & 0.53 \\
\hline 9.2 Payment for kind of need & 0.45 & 0.52 & 0.69 & 0.33 & $\overline{0.51}$ & 0.75 & 0.48 & 0.36 & 0.49 & 0.42 \\
\hline Cluster frequency & 19 & 24 & 22 & 10 & 7 & 4 & 6 & 4 & 10 & Total 106 \\
\hline
\end{tabular}

Source: own research data. grey background I. —minimal differences; grey background II. —maximal differences;

1. up to 8.2: horizontal direction: bold = max., underlined = min.; 9.1: horizontal direction: bold $=$ min., underlined $=$ max. (totally new need $\leftrightarrow$ the same need) —new needs are preferred; 9.2: horizontal direction: bold $=$ min., underlined $=\underline{\text { max }}$. (basic needs $\leftrightarrow$ higher needs) —basic needs are preferred; $x, x x$-maximal value along the vertical direction.

\subsection{Overall Analysis of the Research Sample}

The research sample is divided into nine clusters. The three clusters are large $(1,2,3)$ and account for $61.3 \%$ of the total sample. The remaining six clusters $(38.7 \%)$ range in size from four to ten start-ups. The small frequency of a cluster does not necessarily denote insignificance, because start-ups are companies in rapid development and their presence in the cluster may change, but even more important is the argument that even a small cluster on the edge of a research sample can represent a business model that is perhaps unusual, innovative and unique.

The differences between clusters are small in criteria of imitability of resources, customer relationships, and the ratio of cost and price (0.11-0.16). Larger differences are in the criteria of scarcity of resources, the ratio of fixed and variable costs, deliveries from partners, payment for the type of 
need, differentiation and the number of partners (0.31-0.5). The biggest differences are in the criteria of the focal point of operational processes, payment for value/benefit, segmentation, the main distribution channel and the extent of business processes (0.53-0.83).

Some differences inside the cluster also attract attention. In cluster 1 , the most prominent criterion is differentiation (0.82), although clusters 4 and 6 have even greater differentiation. In cluster 3 , the most significant criterion is the payment for the type of need (0.69), although cluster 6 has an even higher value of this criterion. Cluster 7 has the most significant criterion of the ratio between fixed and variable costs (0.73), but cluster 5 has an even higher value of this criterion.

In each cluster, one to three criteria occur with a maximum value, except for cluster 3 (it does not contain a single maximum value), and one to four criteria with the smallest value, with the exception of cluster 2 (it does not contain a single minimum value). Some criteria and their maximum values express the generally accepted quality and desired level, e.g., differentiation (0.95), scarcity of resources (0.85), imitability (0.71), cost and price ratio (0.66), fixed and variable cost ratio (0.83), and other criteria expressing a certain property of the model, but determining the ideal state probably does not make sense and their size is a matter of discussion or a specific situation, e.g., segmentation (0.9), customer relations (0.59), main distribution channel (0.85), extent of operational processes (0.94), focal point of operational processes (0.93), number of partners (0.66), deliveries from partners (0.79), payment for value/benefit (0.4) and payment for type of need (0.33).

\subsection{Characteristics of Clusters}

Cluster 1 (19 start-ups) — a minimalist autonomous model that better or more cheaply satisfies the ordinary basic needs with higher differentiation.

Analytical description: The model has dominant relationships with customers, but the differences from other start-ups are small (0.57). It has a dominant position in the imitability of resources, hence resources are resistant to imitation, but the differences from other start-ups are again small $(\mathbf{0 . 7 1})$. It has a small range of operational processes $(\underline{0.12})$ and a small number of partners $(\underline{0.16})$ who supply the missing resources $(\underline{0.38})$.

Summary characteristics: Slightly exceptional customer relationships and slightly exceptional resilience to resource imitation. The smallest range of operational processes and the least number of partners who supply mainly the missing resources. Payment for better or cheaper satisfaction of the ordinary need, payment for practical benefits and experiences.

Example: Exponea offers a tool to automate digital marketing and personalize communication across all channels. It works on the basis of machine learning and artificial intelligence algorithms. Superscale helps increase the revenue of mobile games developers and publishers. In the environment of digital products, which are also games, a lot of data about customer behaviour are available.

Cluster 2 (24 start-ups) - a maximalist autonomous model that better or more cheaply satisfies the ordinary basic and higher needs with higher differentiation.

Analytical description: The model has dominant relationships with customers, but the differences from other start-ups are small (0.58). It dominates in operational processes with a large range of operational processes $(\mathbf{0 . 9 4})$ and commands, and controls the focal point of almost the entire operational process (0.93).

Summary characteristics: Slightly exceptional customer relationships, the largest range of operational processes and control of almost the entire operational process. Payment for better or cheaper satisfaction of the ordinary need, payment for practical benefits and experiences.

Example: Pygmalios has developed software that analyses in detail the movement and purchase of visitors in a traditional store. It processes customer behaviour data in real time and sends the results to the merchant to better satisfy the customer while increasing sales. Powerlogy has brought the concept of improved food to active people. Powerlogy products are unique in that they have undergone comprehensive development and testing. They are made only from original raw materials that meet demanding quality criteria. 
Cluster 3 (22 start-ups) —an indistinct minimalist model with higher fixed costs, which better or more cheaply satisfies the ordinary higher needs.

Analytical description: The model has a small range of operational processes $(\underline{0.15})$ and dominates in fixed costs $(\underline{0.46})$.

Summary characteristics: The smallest range of operating processes and the highest ratio of fixed and variable costs. Payment for better or cheaper satisfaction of the ordinary need, payment for experiences and comfort.

Example: Boataround mediates the rental of boats and yachts through its own reservation system, mainly for entertainment and recreation. The world's original portal offers a selection of a huge number of boats in a very simple way, with high quality customer service throughout the rental period (24/7) and in 17 world languages. It works directly with yacht owners and can therefore offer not only the best rental price, but also true and verified information without any surprises on site. eDocu created a system that transparently aggregates and provides information about objects and devices. A QR code is placed on the object, which, after scanning, provides the necessary information, e.g., date of manufacture, instructions for use, service book, revisions, maintenance records, supplier contacts, etc. The eDocu information system is not just a passive source of information. Using, e.g., smartphone, data can be inserted into and deleted out of the system too.

Cluster 4 (10 start-ups)—a highly differentiated and open/partnership model that better or more cheaply satisfies the ordinary basic needs.

Analytical description: The model dominates among other clusters in differentiation (0.90) and in the number of partners (0.63). It earns on payments for health and safety and practical benefits $(\underline{0.33})$. The range of operational processes $(\underline{0.12})$ is small and their focal point is in the middle of the full range of processes $(\underline{0.44})$.

Summary characteristics: Exceptional differentiation and a large number of partners. Very small range of operational processes with a focus in their centre (prototyping). Payment for better or cheaper satisfaction of the ordinary need, payment for health, safety and practical consumer benefits.

Example: MultiplexDX is developing an innovative patent-protected diagnostic test for cancer patients. Its advantage lies in two technologies that eliminate the occurrence of diagnostic errors. The accuracy of the method after the end of development should reach $99 \%$. Current methods give erroneous results in 30 to $50 \%$ of cases. The test provides an answer as to whether it is worth the patient undergoing chemotherapy. Another benefit is personalized diagnostics that properly set up chemotherapy so that the patient receives only as much drug as he needs to kill the tumour.

Cluster 5 (seven start-ups) - a minimalist model with scarce resources, low costs and an emphasis on variable costs, which more comfortably satisfies the ordinary basic and higher needs.

Analytical description: The model dominates in the scarcity of resources (0.79) and achieves the lowest costs compared to the price (0.66), although the differences in the cost and price ratio from other start-ups are small. At the same time, it reaches the largest share of variable costs (0.83) among the examined start-ups. Customer relations are less personal $(\underline{0.43})$, but the differences between this criterion and other start-ups are small. The main distribution channel is mainly direct $(\underline{0.23})$ and the range of operational processes is short $(\underline{0.16})$. The model earns on payments for the same, but more accessible, prompt or faster satisfaction of the ordinary need (0.93).

Summary characteristics: The most rare sources, high variable costs in relation to fixed costs, low total costs, direct distribution, short, very incomplete processes. Payment for the same, but faster satisfaction of the ordinary need, payment for practical benefits and experience.

Example: Vectary provides a cloud-based 3D modelling tool for people who have no experience modelling complex shapes. Vectary helps creators, do-it-yourself masters, and self-taught people around the world to model and offers them various ways to easily shape the designs of objects in their browser. This new concept speeds up designing and is easy to use on a mass scale.

Cluster 6 (4 start-ups) - a highly differentiated and partner model with almost complete customization, which better or more cheaply satisfies the original higher needs. 
Analytical description: The model has a very noticeable differentiation $(\mathbf{0 . 9 0})$ and segmentation, which is up to the top limit of customization (0.95). Deliveries from partners are used for the realization of products and services and their sale $(\mathbf{0 . 7 9 )}$. The model shows higher costs in relation to the price $(\underline{0.5})$, but the difference compared to other start-ups is small. The main distribution channel is chiefly direct $(\underline{0.25})$ and the model earns on payments for comfort, relaxation, entertainment $(\underline{0.75})$.

Summary characteristics: Considerable differentiation, almost complete customization, strong cooperation with partners in the realization and sale of production, direct distribution, slightly higher costs. Payment for better or cheaper satisfaction of the ordinary need, payment especially for comfort, relaxation, entertainment.

Example: Zelená pošta (Green Mail) offers an original combination of postal and electronic delivery services. The biggest benefit of the new service is the relief from administrative mail processes. The possibility of switching to electronic delivery of consignments is also attractive, while each electronic consignment is available for the recipient in his account on zelenaposta.sk, and at the same time, it is sent to his electronic address.

Cluster 7 (six start-ups) - a model of close relationships with a wider circle of customers, which more cheaply meets average needs on the base of unexceptional resources and higher fixed costs.

Analytical description: The model has the best relationships with customers (0.59), but the advance of this criterion over other groups of start-ups is small. Segmentation is relatively small $(\underline{0.33})$. The model has the least rare resources $(\underline{0.45})$ of all clusters.

Summary characteristics: Excellent customer relations, narrow segmentation range and least scarce resources. Payment for the same, but cheaper satisfaction of the ordinary need, cost savings, payment for practical benefits and experience.

Example: Octago develops and manufactures street exercise constructions, which it places in playgrounds, parks and other suitable public areas. The crossbars and supporting columns are connected by an original ring in the shape of an eight angle. In addition to building playgrounds to exercise with their own weight, the start-up offers an experience of active holidays and contributes to the development of sport in towns and schools.

Cluster 8 (4 start-ups) - a minimalist model with scarce resources and indirect distribution, which better satisfies the ordinary basic needs.

Analytical description: The model dominates with its rarity $(\mathbf{0 . 7 6})$ and works with a relatively indirect distribution channel $(\mathbf{0 . 8 5})$. The range of operational processes is very short $(\underline{0.11})$ and their centre of gravity is close to the centre ( $\underline{0.4})$ of the complete chain of operational processes. The model earns by paying for better, greater satisfaction of the ordinary need, for more utility and, partly, cheaper satisfaction of the ordinary need (0.44). It is paid for satisfying the need, which is sustaining health, increasing safety and concrete practical benefit (0.36).

Summary characteristics: Indirect distribution, distinctive rarity, very short operational process with a focal point in the middle. Payment for better, greater satisfaction of the ordinary need and more benefit, payment for health, safety and practical benefit.

Example: VIOU develops a smart bracelet that monitors the falls of seniors, GPS position, body temperature, pulse rate and other critical data that signal a serious medical condition or even death. The device sends data via the GSM network in the form of SMS to persons who are responsible for seniors. The senior is alerted to the emergence of a crisis situation by sound, vibration of the bracelet and a visual announcement on the display.

Cluster 9 (10 start-ups)—a maximalist model with the longest processes and the largest number of partners, which satisfies newer practical needs.

Analytical description: The model has the largest range of operational processes $(0.9)$ and the largest number of partners (0.66). It has the most endangered resources by imitation $(\underline{0.6})$, but the differences between this criterion and other clusters are small. It is paid for the value/benefit, which is health, safety and practical benefit $(\underline{0.40})$. 
Summary characteristics: The largest range of operational processes and the largest number of partners, the easiest imitation of resources. Payment for satisfying a newer need and more benefit from the ordinary need, payment for practical benefit.

Example: Slido has developed an application that allows each participant to be involved in a debate at conferences and lectures. The dozen conference will turn into an interesting event where people will not fall asleep from boredom. Thanks to Slido, the common conference turned into an interactive event that attracted participants, because they were able to use the results obtained from the application in real time during the conference. The organizers need the standard equipment only.

\section{Discussion}

The research brought new and original knowledge about business models of start-ups, which are divided into nine clusters respective to species. It fulfilled the goal to divide business models of start-ups into groups/clusters, and thus better understand their attributes. The identified clusters represent distinctive business models with several different parameters, which bring a different, new interpretation of the models compared to their verbal descriptions. They are the result of the intersection of subjective entrepreneurial creativity and objective business circumstances.

The identified clusters are difficult to compare with other types of business models, because their vehicle is start-ups and models are assembled according to measurable criteria. From the literature, the typology of Osterwalder and Pigneur (2009, pp. 56-108) is known, who identified five concepts, namely unbundling business model, the long tail, multi-sided platforms, free as a business model and open business models. However, these models are not described by a unified set of criteria, if we do not mean the concept of canvas, which is, however, a visualization and not a real model. Gassmann et al. identified fifty-five real models that are unified by the visualization scheme of the business model triangle (Gassmann et al. 2014, p. 6). It describes who the target customers are, what the value is offered, how this value is created and how the profit is generated. However, the identified models are not arranged in groups; they are presented as a list without an internal structure. Baden-Fuller et al. (2017), based on a study of the literature, described four basic types of business models, namely dyadic product, dyadic solutions, triadic matchmaking and triadic multisided. Models are ranked according to their ability to create value for the customer and the resulting profit. These models are not the result of empirical studies, which does not reduce their value, but the absence of explicit measurable criteria makes it impossible to compare them with the identified nine clusters. Foss and Saebi (2017a, 2017b) also point out the need for dimensioning of business models in their studies.

Two studies have been noticed that identified business models using clusters. The first study (Liu et al. 2018) examined business models in the real estate industry and described the business model using seven criteria, resulting in five clusters (models). The criteria of the models are adapted to the industry, and therefore the clusters cannot be compared with the submitted research results. The second study (Beinke et al. 2018) examined business models in the financial sector. The business model was described using twenty-four criteria and the result is seven clusters (models). Comparison with the presented research results is impossible due to the different concept of displaying the business model.

For a better and more comprehensive understanding of the whole research sample and the examined clusters, four groupings were formed, which combine several similar types of business models.

Grouping A (52 start-ups/49.05\%) is characterized by a model with a small range of processes, which should be a natural feature of start-ups given their limited resources, technological and entrepreneurial experience. Clusters 1, 5 and 8 are connected by differentiation and its assumption, which are scarce resources. Cluster 3 is quite numerous, but unlike clusters 1,5 and 8 , it is not conspicuous, which weakens it.

Cluster 1 (19 start-ups) - a minimalist autonomous model that better or more cheaply satisfies the ordinary basic needs with higher differentiation. 
Cluster 5 (seven start-ups)—a minimalist model with scarce resources, low costs and an emphasis on variable costs, which more comfortably satisfies the ordinary basic and higher needs.

Cluster 8 (four start-ups)—a minimalist model with scarce resources and indirect distribution, which better satisfies the ordinary basic needs.

Cluster 3 (22 start-ups) —an indistinct minimalist model with higher fixed costs, which better or more cheaply satisfies the ordinary higher needs.

Grouping B (34 start-ups/32.1\%) is characterized by a model with a large range of processes, which is unusual for a small emerging enterprise if this extent is not provided with a larger number of partners (cluster 2). Conversely, cluster 9 provides service for long processes with the largest number of partners in the entire research sample.

Cluster 2 (24 start-ups) - a maximalist autonomous model that better or more cheaply satisfies the ordinary basic and higher needs with higher differentiation.

Cluster 9 (10 start-ups) - a maximalist model with the longest processes and the largest number of partners, which satisfies newer practical needs.

Grouping C (14 start-ups/13.2\%) is characterized by a model with considerable differentiation, which is expected from the start-ups, but in this case it is focused on the ordinary needs, which explains the emphasis on high differentiation, although focusing on the new needs would significantly increase the robustness of the business model.

Cluster 4 (10 start-ups) - a highly differentiated and open/partnership model that better or more cheaply satisfies the ordinary basic needs.

Cluster 6 (four start-ups) - a highly differentiated and partnership model with almost complete customization, which better or more cheaply satisfies the ordinary higher needs.

Grouping D (six start-ups $/ 5.7 \%$ ) is evidently different from the previous groups, because its model is based on cultivating relationships with customers, cheap satisfaction of needs and uses common resources. These features are not very associated with the concept of a start-up.

Cluster 7 (six start-ups) - a model of close relationships with a wider range of customers, which more cheaply meets average needs based on commonplace resources and higher fixed costs.

Half of the research sample of start-ups (grouping A) chooses a lean model that is in line with the micro size of the company. This choice is natural and realistic, because it corresponds to the competencies and possibilities of the founders. A small start-up is aware of the need for differentiation, but in this effort, it is limited by its modest resources, which will eventually lead a start-up to less differentiation and an undesirable increase in fixed costs (cluster 3 ).

One third of start-ups (grouping B) choose a model with an almost complete operational process, respective to value chain. At first glance, this choice contradicts the possibilities of the micro-size of the company, and therefore perhaps the only explanation is the effort to maintain control over the company. This autonomy may indeed lie in protecting a business idea from imitation, although the originality of the vast majority of ideas does not confirm this, or the reason is the reluctance to share governance over the company.

Less than $15 \%$ of start-ups (grouping C) choose a model that is characterized by high differentiation. This choice expresses the high ambitions of the founders, as such an orientation is both entrepreneurially and societally desirable, but at the same time there is a suspicion that the founders do not want to take extreme risks with highly differentiated ideas because they want to satisfy mostly ordinary basic needs, so they do not dare to discover or create any blue oceans (Kim and Mauborgne 2017).

Few more than $5 \%$ of start-ups (Grouping D) do not have a pioneering and courageous approach to their product. Their distinctive features are good customer relations. However, it is not excluded that innovative customer relationships can become a central block of the model and a significant source of revenue.

The results of the research show that business models are quite diverse, and that their dissimilarity is contrary to the assumption that very small and emerging companies are very similar to each other and the differences begin to manifest themselves only in their maturation and maturity. Significant 
dividing planes represent the extent of internal processes, dependence on partners, differentiation, method of distribution and segmentation. Surprisingly, there is a little difference in finding or creating new and original needs.

Entrepreneurial practice is mainly interested in a kind of normative result or ideal parameters of the business model, which could be high differentiation, short processes and higher cooperation with partners, satisfying new original needs, rare and difficult to imitate resources, low cost/price ratio, low ratio of fixed and variable costs, payment for a new type of benefit, or initially narrow segmentation with the possibility of later expansion.

\section{Conclusions}

The goal of the research was achieved, but a larger number of identified types of business models made their interpretation difficult. This is probably also a consequence of the nature of the start-up business, which is immature, often marked by unjustified enthusiasm, amateurism, inexperience, experimentation and insufficient business professionalism. The result is a relatively diverse business modeling, although the differences are not very large.

The result of the research is nine types of business models of start-ups, which are grouped into four groupings for better transparency. The cluster analysis showed the biggest and smallest differences in the models, and the upper and lower limits of the models, which, however, may not be definitive, they show the factual state of affairs, which can be overcome by innovation. The models differ the most in the extent of operational processes, segmentation and distribution; they differ the least in customer relations, cost/price ratio and protection against imitation, but in individual cases, differentiation, extent of operational processes and fixed and variable cost ratio approach the maximum values, in turn, the extent of operational processes and the number of partners record the smallest individual values.

The identified models have a generic character; they are not committed to boundary conditions, e.g., industry, technology, qualifications and experience of the founder. They are the essence of entrepreneurial effort, they provide a conception/notion of how entrepreneurs/start-uppers materialize their ideas and intentions, and thus allow followers to avoid lengthy and possibly risky experimentation. The identified types of business models can serve as universal models of existing practice and a comparative basis for elementary entrepreneurs. At the same time, however, there is always the possibility of an independent choice of business model according to individual values of criteria, e.g., based on canvas visualization.

The limitation of the research was the size of the research sample, which was given by the work capacity of the research team. The size of the research sample did not provide the possibility of profiling, e.g., according to the industry, the age of the startup, or the originality of the business idea. On the other hand, the non-profiling of the research sample enabled a general and generic view of the business models of start-ups.

Another direction of research may be to overcome existing limits, i.e., to enlarge the sample and confirm the existing results, to profile the sample(s) by industry, to examine differences between models with generic and industry background, to examine in more detail the relationship between need, value, product, sales and profit, which is absolutely essential for the business model. It is also possible to continue a deeper analysis of clusters and examine their effectiveness and business success.

The practical use of the identified clusters lies in the fact that they are a reflection of the real behaviour of start-ups, set real parameters of business models, and therefore provide the founders of start-ups with proven patterns, whose boundaries are probably not definitive. Due to the pioneering nature of research, it is necessary to continue scientific cognition of business models of start-ups, which will confirm, correct or change the existing knowledge on this topic.

Author Contributions: Conceptualization, Š.S., Literature review, R.B. and I.M.H., Methodology, Š.S., Field research and data collection, I.M.H., R.B. and Š.S., Data processing: K.M., Interpretation of data analysis and discussion, Š.S., Writing-Review and Editing, ̌̌.S. All authors have read and agreed to the published version of the manuscript. 
Funding: This research was funded by the Scientific grant agency of Ministry of Education of Slovak Republic and Slovak Academy of Sciences (VEGA), grant number 1/0063/19.

Conflicts of Interest: The authors declare no conflict of interest.

\section{References}

Afuah, Alan. 2003. Business Models: A Strategic Management Approach. New York: McGraw-Hill Companies. Angelist. 2019. Available online: https://angel.co/companies (accessed on 20 June 2020).

Baden-Fuller, Charles, and Vincent Mangematin. 2013. Business models: A challenging agenda. Strategic Organization 11: 418-27. [CrossRef]

Baden-Fuller, Charles, Alessandro Giudici, Stefan Haefliger, and Mary Morgan. 2017. Business models and value. Academy of Management Proceedings 2017. [CrossRef]

Beinke, Jan Heinrich, Nguyen Ngoc, and Frank Teuteberg. 2018. Towards a business model taxonomy of start-ups in the finance sector using block-chain. Paper presented at Thirty Ninth International Conference on Information Systems, San Francisco, CA, USA, December 13-16; pp. 157-66. Available online: http: //toc.proceedings.com/47764webtoc.pdf (accessed on 18 June 2020).

Blank, Steve. 2013. Why the lean start-up change everything. Harvard Business Review 2013: 65-72.

Bryant, Scott, Karla Straker, and Cara Wrigley. 2018. The typologies of power: Energy utility business models in an increasingly renewable sector. Journal of Cleaner Production 195: 1032-46. [CrossRef]

CB Insight. 2018. Available online: https://www.cbinsights.com/research/startup-failure-reasons-top/ (accessed on 20 June 2020).

Corbett, Andrew C., and Jerome A. Katz. 2016. Models of Start-Up Thinking and Action: Theoretical, Empirical and Pedagogical Approaches. Bingley: Emerald Publishing Limited, ISBN1 978-1-78635-486-0. ISBN2 978-1-78635-485-3.

Donner, Mechthild, Romane Gohier, and Hugo deVries. 2020. A new circular business model typology for creating value from agro-waste. Science of the Total Environment 716. [CrossRef]

Downes, Larry, and Paul Nunes. 2018. Finding Your Company's Second Act. Harvard Business Review 2018: 98-107. Available online: https://hbr.org/2018/01/finding-your-companys-second-act (accessed on 22 June 2020).

Foss, Nicolai J., and Tina Saebi. 2017a. Fifteen years of research on business model innovation: How far have we come, and where should we go? Journal of Management 43: 200-27. [CrossRef]

Foss, Nicolai J., and Tina Saebi. 2017b. Business models and business model innovation: Between wicked and paradigmatic problems. Long Range Planning. [CrossRef]

Franco, Alejandro A., Marie Liesse Doublet, and Wolfgang G. Bessler. 2016. Physical Multiscale Modelling and Numerical Simulation of Electrochemical Devices for Energy Conversion and Storage. London: Springer. [CrossRef]

Gassmann, Oliver, Karolin Frankenberger, and Michaela Csik. 2014. The Business Model Navigator. London: Pearson.

Ghezzi, Antonio, and Angelo Cavallo. 2020. Agile business model innovation in digital entrepreneurship: Lean start-up approaches. Journal of Business Research 110: 519-37. [CrossRef]

Global Start-up Ecosystem Report. 2019. Available online: https://startupgenome.com/reports/global-startupecosystem-report-2019 (accessed on 21 June 2020).

Graham, Paul. 2018. Start-up = Growth. Available online: http://paltelfoundation.ps/uploads/No._16_-_Startup= Growth.pdf (accessed on 21 June 2020).

Haaker, Timber, Harry Bouwman, Wil Jansen, and Mark de Reuver. 2017. Business model stress testing: A practical approach to test the robustness of a business model. Futures 89: 14-25. [CrossRef]

Hansen, Erik G. 2018. Ecopreneurs' creation of user business models for green tech: An exploratory study in E-Mobility. International Journal of Entrepreneurial Venturing 10: 32-55. [CrossRef]

Henry, Marvin, Thomas Bauwens, Marko Hekkert, and Julian Kirchherr. 2020. A typology of circular start-ups: An Analysis of 128 circular business models. Journal of Cleaner Production 245. [CrossRef]

Hokkanen, Laura, Yueqiang Xu, and Kaisa Väänänen. 2016. Focusing on user experience and business models in Startups: Investigation of two-dimensional value creation. In AcademicMindtrek'16, Proceedings of the 20th International Academic Mindtrek Conference. Tampere: Association for Computing Machinery, pp. 59-67. [CrossRef] 
Iwu, Chux Gervase. 2017. Sustaining small businesses in emerging economies: An examination of the pre and post start-up ramifications. Problems and Perspectives in Management 15: 227-36. [CrossRef]

Johnson, Mark W., Clayton M. Christensen, and Henning Kagerman. 2008. Reinventing your business model. Harvard Business Review 51. Available online: https://hbr.org/2008/12/reinventing-your-business-model (accessed on 12 June 2020).

Kim, Chan W., and Renee Mauborgne. 2017. Blue Ocean Shift: Beyond Competing_-Proven Steps to Inspire Confidence and Seize New Growth. New York: Hachette Books.

Liu, Guiwen, Kaijian Li, Asheem Shrestha, Igor Martek, and Yang Zhou. 2018. Strategic business model typologies evident in the Chinese real-industry. International Journal of Strategic Property Management 22: 501-15. [CrossRef]

Lüdeke-Freund, Gold Stefan Florian, and Nancy M. P. Bocken. 2018. A review and typology of circular economy business model patterns. Journal of Industrial Ecology 23. [CrossRef]

Magretta, Joan. 2010. Why business models matter. Harvard Business Review, 8-10. Available online: https: //store.hbr.org/product/harvard-business-review-may-2010/BR1005 (accessed on 15 June 2020).

Muñoz, Pablo, and Boyd Cohen. 2017. Mapping out the sharing economy: A configurational approach to sharing business modelling. Technological Forecasting and Social Change 125: 21-37. [CrossRef]

Muramalla, Venkata Sai Srinivasa Rao, and Ateeq Mesfer Al-Hazza. 2019. Entrepreneurial strategies and factors stimulate the business of tech start-ups. International Journal of Financial Research 10: 360-70. [CrossRef]

Osterwalder, Alexander, and Yves Pigneur. 2009. Business Model Generation. Available online: https: //www.academia.edu/23846689/BUSINESS_MODEL_GENERATION_OSTERWALDER (accessed on 11 August 2020).

Rappa, Michael. 2010. Business Models on the Web. Managing the Digital Enterprise. Available online: http: //home.ku.edu.tr/ \{\}daksen/mgis410/materials/Business_Models_on_the_Web.pdf (accessed on 18 June 2020).

Rask, Morten, and Günzel-Jensen Franziska. 2019. Business model design and performance in nascent markets. Management Decision 58: 927-47. [CrossRef]

Remane, Gerrit, Björn Hildebrandt, Andre Hanelt, and Lutz Kolbe. 2016. Discovering new digital business model types-A study of technology start-ups from the mobility sector. PACIS 2016 Proceedings. 289. Available online: https://aisel.aisnet.org/pacis2016/289 (accessed on 20 June 2020).

Ritter, Thoms, and Christopher Lettl. 2017. The wider implications of business-model research. Long Range Planning 51: 1-8. [CrossRef]

Rougès, Jean Francois, and Benoit Montreuil. 2014. Crowdsourcing delivery: New interconnected business models to reinvent delivery. Paper presented at 1st International Physical Internet Conference, Quebec City, QC, Canada, May 28-30; Available online: https://www.cirrelt.ca/ipic2014/pdf/1027a.pdf (accessed on 22 June 2020).

Rückeshäuser, Nadine. 2017. Typology of distributed ledger based business models. Paper presented at 25th European Conference on Information Systems (ECIS), Guimarães, Portugal, June 5-10; pp. 2202-17. Available online: http://aisel.aisnet.org/ecis2017_rp/140 (accessed on 21 June 2020).

Sahut, Jean Michel, Lubica Hikkerova, and Moez Khalfallah. 2013. Business model and performance of firms. International Business Research 6. [CrossRef]

Sahut, Jean Michel. 2011. Business model of internet banks. SSRN Electronic Journal. [CrossRef]

Schane, Scott A., and Karl T. Ulrich. 2004. Technological Innovation, Product Development, and Entrepreneurship in Management Science. Management Science 50: 133-44. Available online: sjbae.pbworks.com/f/Shane Ulrich+2004.pdf (accessed on 22 June 2020). [CrossRef]

Schrage, Michael. 2018. The Right Way for an Established Firm to Do an Innovation Pilot with a Start-up. Harvard Business Review. March 30. Available online: https://hbr.org/2018/05/the-right-way-for-an-established-firmto-do-an-innovation-pilot-with-a-startup (accessed on 21 June 2020).

Schweizer, Lars. 2005. Concept and evolution of business models. Journal of General Management. [CrossRef]

Slávik, Štefan. 2019. The Business model of start-up—Structure and consequences. Administrative Sciences 9: 69. [CrossRef]

Stankovičová, Iveta, and Mária Vojtková. 2007. Viacrozmerné Štatistické Metódy s Aplikáciami. (Multidimensional Statistical Methods with Applications). Bratislava: IURA Edition. 
Surbhi, Jain. 2016. Growth of Start-Up Ecosystems in India. International Journal of Applied Research 2: 152-54. Available online: http://www.allresearchjournal.com/archives/2016/vol2issue12/PartC/2-12-10232.pdf (accessed on 22 June 2020).

Wirtz, Bernd W. 2019. Digital Business Models: Concepts, Models, and the Alphabet Case Study, 1st ed. Cham: Springer Nature AG. [CrossRef]

Zajac, Pawel. 2015. Evaluation Method of Energy Consumption in Logistic Warehouse Systems. Cham: Springer International Publishing. [CrossRef]

Zepeda, Mara, and Jennifer Brandel. 2019. We Need More Start-ups That Don't Prioritize Growth Above All Else. Harvard Business Review. September 10. Available online: https://hbr.org/2019/09/we-need-more-startupsthat-dont-prioritize-growth-above-all-else (accessed on 21 June 2020).

Zhang, Shixin Ivy. 2018. The business model of journalism start-ups in China. Digital Journalism 7: 614-34. [CrossRef]

(C) 2020 by the authors. Licensee MDPI, Basel, Switzerland. This article is an open access article distributed under the terms and conditions of the Creative Commons Attribution (CC BY) license (http://creativecommons.org/licenses/by/4.0/). 